NASA Contractor Report 3956

NASA-CR-395619860016816

\title{
Analysis of Transitional Separation Bubbles on Infinite Swept Wings
}

R. L. Davis and J. E. Carter

CONTRACT NAS1-16585

JUNE 1986

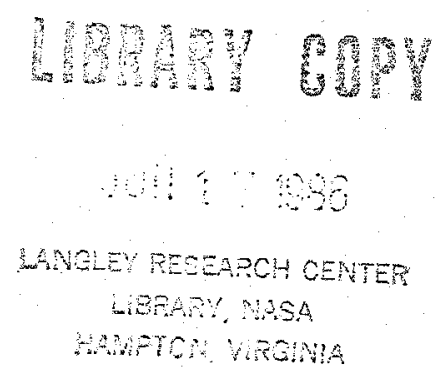

N/Sก 

NASA Contractor Report 3956

\section{Analysis of Transitional Separation Bubbles on Infinite Swept Wings}

R. L. Davis and J. E. Carter

United Technologies Research Center

East Hartford, Connecticut

Prepared for

Langley Research Center

under Contract NAS1-16585

\section{N/SA \\ National Aeronautics \\ and Space Administration \\ Scientific and Technical Intormation Branch}


SUMMARY • • . . . . . . . . . . . . . . . . . . . . . . . . . 1

INTRODUCTION . . . . . . . . . . . . . . . . . . . . . . . . . . . . 1

LIST OF SYMBOLS • . • . . . . . . . . . . . . . . . . . . . . . 2

INVISCID-VISCOUS INTERACTION ANALYSIS . . . . . . . . . . . . . . . . 3

Viscous Analysis . . . . . . . . . . . . . . . . . . . . . . 4

Turbulence Model . . . . . . . . . . . . . . . . . 8

Transition Prediction . . . . . . . . . . . . . . . . . . 8

Wall Suction . . . . . . . . . . . . . . . . . . . . 11

RESULTS • . . . . . . . . . . . . . . . . . . . . . . . 11

Natural Transition Model Computations . . . . . . . . . . . . 12

Gaster Experiment . . . . . . . . . . . . . . . . . . 12

Gault NACA-0010 Airfoil . . . . . . . . . . . . . . . . 12

Gault NACA-66 $3-018$ Airfoil . . . . . . . . . . . . . . . 13

Infinite Swept Wing . . . . . . . . . . . . . . . . . . . 14

Horton Experiment . . . . . . . . . . . . . . . . . . 14

Influence of Wall Suction . . . . . . . . . . . . . . . . 16

CONCLUDING REMARKS . . . . . . . . . . . . . . . . . . . . . 17

ACKNOWLEDGEMENTS . . . . . . . . . . . . . . . . . . . . . 17

REFERENCES . . . . . . . . . . . . . . . . . . . . . . 18

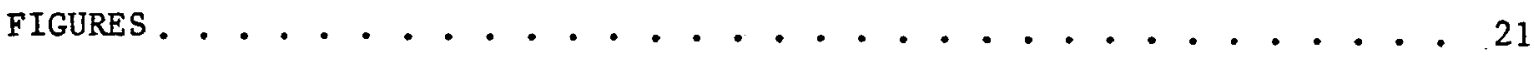


A previously developed two-dimensional local inviscid-viscous interaction technique for the analysis of airfoil transitional separation bubbles, ALESEP (Airfoil Leading Edge Separation), has been extended for the calculation of transitional separation bubbles over infinite swept wings. As part of this effort, Roberts' empirical correlation, which is interpreted as a separated flow empirical extension of Mack's stability theory for attached flows, has been incorporated into the ALESEP procedure for the prediction of the transition location within the separation bubble. In addition, the viscous procedure used in the ALESEP technique has been modified to allow for wall suction. A series of two-dimensional calculations are presented as a verification of the prediction capability of the interaction technique with the Roberts transition mode1. Numerical tests have shown that this two-dimensional natural transition correlation may also be applied to transitional separation bubbles over infinite swept wings. Results of the interaction procedure are compared with Horton's detailed experimental data for separated flow over a swept plate which demonstrates the accuracy of the present technique. Wall suction has been applied to a similar interaction calculation to demonstrate its effect on the separation bubble. The principal conclusion of this paper is that the prediction of transitional separation bubbles over two-dimensional or infinite swept geometries is now possible using the present interacting boundary layer approach.

\section{INTRODUCTION}

There has been renewed interest in recent years in the development of Natural Laminar Flow (NLF) airfoils which result in reduced drag from that incurred with turbulent flow airfoils. The performance of these laminar flow airfoils is critically dependent on the location of transition, which as pointed out in a recent study by Obara and Holmes (ref. 1), often occurs due to the separated shear layer of a closed transitional separational bubble. Although this separation bubble is generally of short streamwise extent, it nonetheless is a local site of strongly interacting viscous and inviscid flow which cannot be analyzed by conventional boundary layer analyses as was discussed by Obara and Holmes. Experimental studies (refs. 2 and 7 ) have shown that for high Reynolds number flows, the viscous effects induced by a closed transitional separation bubble are contained within a relatively thin layer near the surface. This type of separated flow is well suited to analysis with interacting boundary layer techniques which model the flow field as separate inviscid and viscous regions coupled together through displacement thickness interaction. Significant developments in theoretical techniques (refs. 8 through 10), based on inviscid-viscous interaction theory, have been 
made for the calculation of two-dimensional transitional separation bubbles. For example, Vatsa and Carter (ref. 10) developed the ALESEP (Airfoil Leading Edge Separation) interaction analysis for the calculation of transitional separation bubbles on airfoils. This technique consists of a finite difference boundary layer scheme coupled to a Cauchy integral perturbation analysis for the inviscid flow using the semi-inverse coupling strategy. The focus of the current investigation has been the further development of this technique for the prediction of transitional separation bubbles. In particular, the ALESEP analysis has been extended to the flow over infinite swept wings with some very encouraging comparisons presented with Horton's (ref. 4) benchmark data to demonstrate this capability. This extension from two-dimensional airfoils to infinite swept wings represents an important first step in the eventual development of a fully three-dimensional analysis. In addition, the present approach has been significantly enhanced by the incorporation of Roberts' (ref. 11) empirical transition criteria for laminar separation bubbles. A brief discussion is presented that links Roberts' correlation for separated flow to Mack's (ref. 12) stability theory for attached flows. Computations are presented for two-dimensional airfoils and infinite swept wing flows that demonstrate the applicability of this correlation provided the free stream turbulence level is known.

\section{LIST OF SYMBOLS}

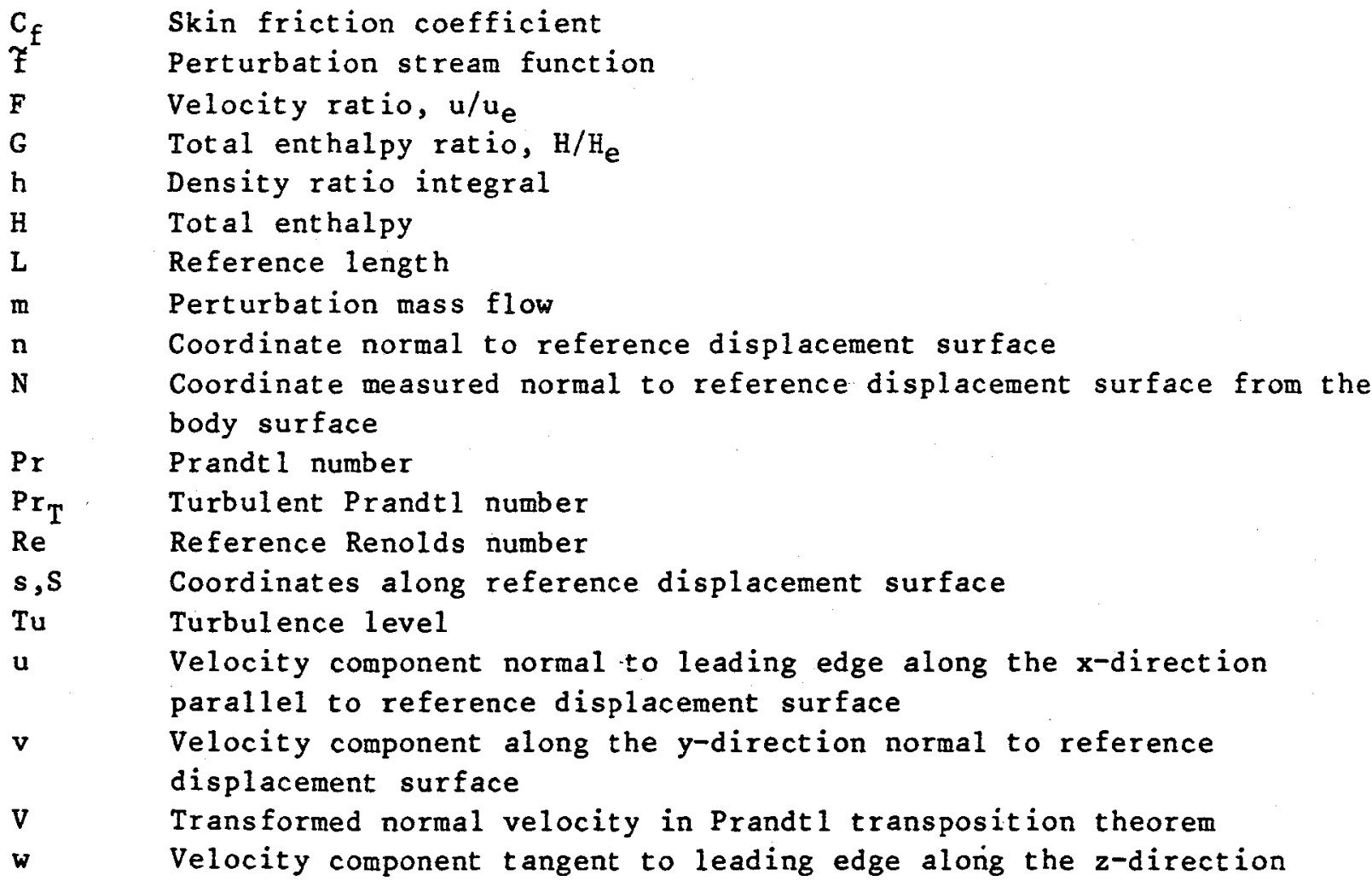




$\begin{array}{ll}\text { W } & \text { Velocity ratio, w/we } \\ \mathbf{x} & \text { Coordinate direction normal to leading edge. } \\ \mathrm{X} & \text { Coordinate direction (absolute frame) parallel to freestream } \\ \text { direction } & \text { Coordinate direction normal to surface } \\ y & \text { Coordinate direction tangent to leading edge } \\ z & \text { Coordinate direction (absolute frame) perpendicular to free stream } \\ z & \text { direction in reference plane of airfoil surface } \\ \beta & \text { Pressure gradient parameter } \\ \delta & \text { Boundary layer thickness } \\ \delta * & \text { Displacement thickness } \\ \varepsilon & \text { Eddy viscosity coefficient } \\ \Lambda & \text { Sweep angle } \\ \eta & \text { Transformed normal coordinate } \\ \nu & \text { Kinematic viscosity coefficient } \\ \mu & \text { Molecular viscosity coefficient } \\ \xi & \text { Transformed tangential coordinate } \\ \rho & \text { Density } \\ \psi & \text { Streamfunction }\end{array}$

\section{Subscripts}

$\begin{array}{ll}e & \text { Edge of boundary layer } \\ \text { I } & \text { Inviscid } \\ \text { ref } & \text { Reference solution } \\ v & \text { Viscous } \\ \mathbf{x} & \text { Component along } x \text { direction } \\ \mathbf{z} & \text { Component along z direction } \\ \infty & \text { Freestream }\end{array}$

\section{INVISCID-VISCOUS INTERACTION ANALYSIS}

In the present inviscid-viscous interaction analysis, the compressible three-dimensional boundary layer equations for infinite swept wings are solved in inverse form iteratively with an incompressible Cauchy integral perturbation analysis for the inviscid flow. Iteration between the inviscid and viscous flow solutions is accommodated through the use of an update formula (ref. 13) which modifies the specified displacement thickness distribution along the $x$-direction, normal to the leading edge of the swept configuration, as shown in figure 1 , based upon the differences between the predicted inviscid and viscous velocities at the edge of the boundary layer in that direction. For infinite swept wings, the two-dimensional Cauchy integral analysis, described in reference 10, remains unchanged along a line perpendicular to the wing leading edge since the spanwise component of the boundary 
layer edge velocity is constant and therefore, is unaffected by the viscous displacement thickness. As shown by Moore (ref. 14), for flows over infinite swept wings, the general three-dimensional displacement thickness reduces to the two-dimensional displacement definition which is based on the u-velocity component in the $x$-direction.

\section{Viscous Analysis}

The viscous solution technique used for the investigation of swept transitional separation bubbles is an extension of the inverse procedure presented by Carter (ref. 15) for two-dimensional flows. The nondimensional boundary layer equations for an infinite swept body are written as follows in terms of the reference displacement surface coordinate system shown in figure 2:

$$
\begin{gathered}
\frac{\partial \rho u}{\partial s}+\frac{\partial \rho v}{\partial n}=0 \\
\rho u \frac{\partial u}{\partial s}+\rho v \frac{\partial u}{\partial n}=\rho e_{e}^{u} \frac{d u e}{d s}+\frac{\partial}{\partial n}\left[\mu \frac{\partial u}{\partial n}-\overline{\rho u^{\prime} v^{\prime}}\right] \\
\rho u \frac{\partial w}{\partial s}+\rho v \frac{\partial w}{\partial n}=\frac{\partial}{\partial n}\left[\mu \frac{\partial w}{\partial n}-\overline{\left.\rho w^{\prime} v^{\prime}\right]}\right. \\
\rho u \frac{\partial H}{\partial s}+\rho v \frac{\partial H}{\partial n}=\frac{\partial}{\partial n}\left[\frac{\mu}{P_{R}} \frac{\partial H}{\partial n}-\overline{\rho v^{\prime} H^{\prime}}+\frac{\mu}{2}\left(1-\frac{1}{P_{R}}\right) \frac{\partial\left(u^{2}+w^{2}\right)}{\partial n}\right]
\end{gathered}
$$

The $\mathrm{v}$-component of velocity and the $n$-coordinate are scaled by $\sqrt{\operatorname{Re}_{\infty}, c}$ where $\operatorname{Re}_{\infty, c}$ is the Reynolds number based upon the freestream flow conditions and the airfoil chord. The boundary conditions imposed on these governing equations are: 


$$
\begin{array}{ll}
\text { at } n=-\delta_{\text {ref }}^{*}, & u=v^{\prime}=w=0 \\
& H \text { or } \frac{\partial H}{\partial n} \text { specified } \\
& u \rightarrow u_{e} \\
\text { at } n \rightarrow \infty, & w \rightarrow w_{e}=\sin \Lambda \\
& H+H_{e}
\end{array}
$$

Equations (1)-(4) are transformed through the use of Levy-Lees type variables:

$$
\xi=\int_{0}^{s} \rho_{e} \mu_{e} e^{u} d s \quad n=\frac{\rho_{e}^{u} e}{m} \int_{-\delta_{r e f}^{*}}^{n} \frac{\rho}{\rho_{e}} d n
$$

where $m=\sqrt{2 \xi}$ for direct formulation

$=\rho e^{u} e^{\delta^{*}}$ for inverse formulation

In order to simplify the boundary conditions, the velocity components are normalized by their corresponding edge values:

$$
F=\frac{u}{u_{e}} \quad w=\frac{w}{w_{e}} \quad G=\frac{H}{H_{e}}
$$

The normal component of velocity is replaced by the introduction of the stream function

$$
\rho v=-\frac{\partial \psi}{\partial s}
$$

in which the stream function is rewritten in terms of a perturbation stream function given by

$$
\tilde{f}=\frac{1}{\sqrt{2 \xi}}[\psi-m F(n-1+h)]
$$


where

$$
h=\int_{0}^{\infty}\left(\frac{\rho e}{\rho}-1\right) d \eta
$$

Use of this perturbation stream function is the key step in this formulation for the imposition of the prescribed displacement thickness. With the continuity equation replaced with $\rho u=\partial \psi / \partial n$ and after use of the Prandt 1 transposition theorem as discussed in reference 15, the governing equations are written in transformed coordinates as:

$$
\begin{aligned}
& \frac{\partial \tilde{f}}{\partial \eta}=\frac{m}{\sqrt{2 \xi}}(1-\eta-h) \frac{\partial F}{\partial \eta} \\
& m^{2} F \frac{\partial F}{\partial \xi}-m \frac{\partial}{\partial \xi}[\sqrt{2 \xi} \mathfrak{I}+m F(n-1+h)] \frac{\partial F}{\partial \eta} \\
& =m^{2} B\left[G-F^{2}\left(1+\frac{\frac{w_{e}^{2}}{u_{e}^{2}}}{1+\frac{\gamma-1}{2} M_{e}^{2}}\right)-W^{2}\left(\frac{\frac{\gamma-1}{2} M_{e}^{2} \frac{w_{e}^{2}}{u_{e}^{2}}}{1+\frac{\gamma-1}{2} M_{e}^{2}}\right)\right]+\frac{\partial}{\partial \eta}\left[\left(1+\frac{\varepsilon}{\mu}\right) e \frac{\partial F}{\partial \eta}\right] \\
& m^{2} F \frac{\partial W}{\partial \xi}-m \frac{\partial}{\partial \xi}[\sqrt{2 \xi} \tilde{f}+m F(n-1+h)] \frac{\partial W}{\partial \eta}=\frac{\partial}{\partial \eta}\left(1+\frac{\varepsilon}{\mu}\right) l \frac{\partial W}{\partial \eta} \\
& m^{2} F \frac{\partial G}{\partial \xi}-m \frac{\partial}{\partial \xi}[\sqrt{2 \xi} \tilde{f}+m F(n-1+h)] \frac{\partial G}{\partial \eta} \\
& =\frac{1}{\mathrm{P}_{\mathrm{R}}} \frac{\partial}{\partial \eta}\left[\ell\left(1+\frac{\varepsilon}{\mu} \frac{\mathrm{P}_{\mathrm{R}}}{\mathrm{P}_{\mathrm{R}_{\mathrm{T}}}}\right) \frac{\partial \mathrm{G}}{\partial \eta}\right] \\
& +\frac{\left(1-\frac{1}{P_{R}}\right)(\gamma-1) M_{e}^{2}}{\left(1+\frac{\gamma-1}{2} M_{e}^{2}\right)\left(u_{e}^{2}+w_{e}^{2}\right)} \frac{\partial}{\partial \eta}\left[\ell\left(u_{e}^{2} \frac{\partial F}{\partial \eta}+w_{e}^{2} W \frac{\partial W}{\partial \eta}\right)\right]
\end{aligned}
$$

where 


$$
\beta=\frac{1}{M_{e}} \frac{d M_{e}}{d \xi} \quad \ell=\frac{\rho \mu}{\rho_{e} \mu_{e}}
$$

In these equations, the Reynolds stresses have been related in the usual manner to the mean velocity and temperature gradients through the use of an eddy viscosity coefficient. The turbulence model used in this investigation will be discussed in the next section. Equations (11) - (14) are solved for $F, W, G, F$, and $\beta$ for a prescribed streamwise distribution of m subject to the following boundary conditions:

$$
\begin{aligned}
& \text { at } \eta=0, \quad F=W=\tilde{f}=0 \\
& G=G_{w} \text { or }\left.\frac{\partial G}{\partial \eta}\right|_{w} \text { specified } \\
& \mathrm{F}=\mathrm{W}=\mathrm{G}+1 \\
& \text { at } n+\infty, \tilde{f}+0
\end{aligned}
$$

These equations $c$ an also be solved in the direct mode with $B$ prescribed and the outer boundary condition, $\mathfrak{F}=0$, eliminated. The numerical solution of these equations for the direct and inverse mode is obtained through the use of an implicit finite difference technique similar to that used by Carter (ref. 15) which is first order accurate in the $\xi$-direction and second order accurate in the $n$-direction.

A windward differencing scheme similar to that described in reference 16 is used in the reversed flow regions for the streamwise convection terms in equations (11) - (14). It was shown in reference 16 that for two-dimensional transitional separation bubbles, the windward differencing approximation produces nearly identical results for the surface pressure and skin friction distributions as that obtained with the FLARE (Reyhner and Flugge-Lotz (ref. 17)) approximation in which the convection terms are set to zero in the separated flow region. However, it was found that the windward differencing scheme produced solutions which differed in the outer part of the flow field away from the surface as compared with solutions using the FLARE approximation; especially as the separation bubble became large. Similar results have been found in the calculation of infinite swept wing separation bubbles. The predicted pressure and skin friction results for infinite swept flows using the windward differencing scheme have been essentially identical to those using the FLARE approximation. The largest differences in predictions 
between these two approaches have been mainly in the spanwise (z-direction) velocity profiles.

\section{Turbulence Model}

In the previous two-dimensional interaction calculations presented in references 10 and 16 , the Cebeci-Smith (ref. 18) turbulence model was used to determine the eddy viscosity coefficient, $\varepsilon$. With the extension of the interaction approach to include flow over infinite swept wings, a three-dimensional version of this model (ref. 19) has been used to calculate the eddy viscosity coefficients in the $x-$ and $z$-directions. In the current investigation, the turbulence field has been assumed to be isotropic.

In contrast to our previous two-dimensional work on transitional separation bubbles, it was found necessary in the present calculations for the Horton swept plate experiment to modify the $\mathrm{Cl}$ auser constant in the outer layer of the turbulence model in order to obtain flow reattachment. Without this increase in the $\mathrm{Clauser}$ constant, reattachment of the flow downstream of transition did not occur leading to stalled flow and subsequent divergence of the numerical calculation. Since the Cebeci-Smith model was originally developed for attached flows, it is expected that some changes in this model are needed for the analysis of separated flows. Kim et al. (ref. 20) deduced from experimental data for the reattaching flow downstream of a backwardfacing step, that the Clauser constant increases from the value of 0.0168 in attached flows to levels as great as 0.085 both upstream and downstream of reattachment. In the present computations corresponding to Horton's swept plate experiment (ref. 4), a Clauser constant of 0.084 was found to produce the best agreement with the experimental pressure distribution and velocity profiles. A similar strategy was described by Cebeci, et al. (ref. 21) for some recent interaction analyses of turbulent separated flow.

\section{Transition Prediction}

Closure of the computation of airfoil transitional separation bubbles requires the use of some transiton criterion that in effect establishes the length of the laminar portion of the separation region as a function of the turbulence level of the external flow.

The variation of transition Reynolds number with free stream turbulence level has been estimated by Mack (ref. 12) for the Falkner-Skan family of laminar boundary layers. Using typical wind tunnel turbulence spectra as input to a growth calculation based on linear stability theory, Mack found that transition due to free stream turbulence for a flat plate boundary layer could be correlated with an amplitude ratio from linear stability theory of $e^{n}$ where 
and $T u$ is the turbulence level. Using this transition criterion, Mack obtained results for the Falkner-Skan family that are shown in figure 3 . The experimental data shown in figure 3 is that taken by Dryden (ref. 22) for flow over a flat plate. The curves are remarkably similar in shape but show significant decrease in transition Reynolds number as the pressure gradient, $B_{h}$, becomes more adverse.

The laminar portion of a separation bubble is not represented within the traditional Falkner-Skan flows. Rather it is better represented by the family of reversed flow solutions to the Falkner-Skan-Hartree equation that were calculated by Stewartson (ref. 23) and by Christian and Hankey (ref. 24). The stability characteristics of these reversed flow profiles were calculated recently by Gleyzes, Cousteix, and Bonnet (ref. 8 ). In principle then, the curves presented by Mack could be extended to cover the Stewartson profiles using the results of reference 8 .

The pressure gradient history of a laminar separation bubble from the point of separation to the transition point is not representable as any single similarity profile of the Stewartson family. It is felt, however, that it is a reproducible composite of them. Thus it can be expected that the transition Reynolds numbers as a function of external turbulence level should be represented by a curve resembling those presented by Mack for the Falkner-Skan family but at a lower level than those for the attached flows. For the present use, this curve will be obtained from experimental results reported in the literature.

Roberts (refs. 11 and 25) put together such a correlation in terms of a turbulence factor based on both turbulence level and scale rather than on turbulence level alone. This representation is very appropriate as it is an approximate way of representing the effects of disturbance spectrum on transition. In any given facility, however, there is usually a one-to-one relation between turbulence level and turbulence factor. Wind tunnels of comparable design would have comparable relationships between turbulence level and turbulence factor. Since the scale of turbulence is not uniformly available for all the experiments considered in developing and applying the correlation, the correlation will be presented in terms of turbulence level alone.

For the calculations presented herein, the transition length has been estimated according to the following form of Roberts' relation: 


$$
\frac{u_{e_{s}{ }^{\ell} t}}{v}=25,000 \log _{10}\left[\operatorname{coth}\left(17.32 \mathrm{~T}_{u_{e}}\right)\right]
$$

where

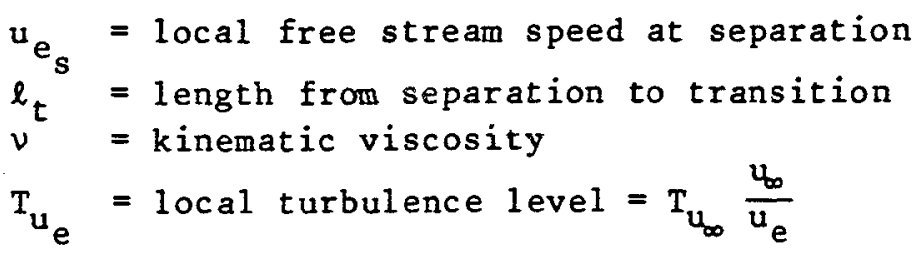

This relation is shown in figure 4 together with the data points from the investigations on which it is based (refs. $2-5$ and $26-28$ ). Because of uncertainties in evaluating some of the points, and because of some scatter in the plot, the above relation must be regarded as provisional pending further detailed study of the data included in figure 4, as well as any other relevant data that may become available. More particularly, transition in many lowturbulence wind tunnels is 1 imited by acoustic disturbances rather than by free stream turbulence so a correlation based on turbulence alone may overestimate the length to transition.

Further, it is felt that the above criterion may also be applied to the separation bubble on a swept wing. The justification is by the following argument. Transition in three-dimensional boundary layers tends to be determined by the component profile that displays the largest growth rate. On a swept wing where the spanwise profile is an attached profile, it is expected that the chordwise separated, reversed flow is less stable than even the crossflow, and so it is recomended that the above criterion be used in estimating the chordwise length to transition.

In the implementation of the Roberts transition correlation into the present viscous analysis, the transition location was allowed to change only during the first 20 global interaction iterations. After the 20th iteration, the transition location was frozen for the remainder of the interaction calculation. It was found from numerical tests that without freezing the transition location at some point during the iterative process, convergence could not be obtained since a limit cycle occurred due to oscillations in the predicted transition location. This approximate treatment should have only a minor impact since the changes in the edge velocity after 20 interaction iterations were small. 


\section{Wall Suction}

A wall suction (or blowing) distribution can be applied to the boundary layer flow through a simple change in the boundary conditions for the perturbation stream functions, $f$. The imposition of prescribed distribution of mass flux normal to the wall, $(\rho v)_{w}$, results in the following surface distribution of the stream function:

$$
\psi_{w}=-\int_{A_{0}}^{A}(\rho v)_{w} d s
$$

where $A_{0}$ is the location of the start of the prescribed wall transportation condition. At the surface the perturbation stream function becomes

$$
\mathfrak{F}(\xi, 0)=\frac{\psi_{\mathrm{w}}}{\sqrt{2 \xi}}
$$

In the inverse mode, which is used in interactive calculations, the value of the stream function at the boundary layer edge is prescribed in terms of the perturbation mass flow parameter, $m$. In the present analysis this boundary condition is imposed through the use of the perturbation stream function which is defined in Eq. (9). At the boundary layer edge

$$
\eta+\infty, \quad \tilde{\mathrm{f}}+\frac{\psi_{w}}{\sqrt{2 \xi}}
$$

If there is no wall transpiration, $\psi_{w}=0$, then the boundary conditions given in equations (20) and (21) revert back to those given in equation (16).

\section{RESULTS}

With the implementation of the Roberts natural transition correlation into the ALESEP inviscid-viscous interaction procedure, a series of two-dimensional cases were calculated and compared to previously published results in references 10 and 16 where transition was prescribed near the "break point" in the experimental pressure distribution. Calculations corresponding to the Gaster (ref. 3) Series I, No. IV experiment and the Gault (ref. 2) modified 
NACA-0010 airfoil and NACA $66,-018$ airfoil experiments were made to evaluate the accuracy of the natural transition model. Upon verification of the Roberts correlation, the extended ALESEP interaction procedure for infinite swept wings was tested against the experimental data of Horton for the separated flow over a swept flat plate. The Roberts correlation was also used in this calculation to determine the transition location. Windward differencing of the convection terms in the boundary layer equations has been used for all the calculations presented herein except where noted. As stated before, similar calculations have been performed with the FLARE approximation and have given essentially identical results in terms of the surface pressure and skin friction distributions. Wall suction was applied to the boundary layer in a similar calculation for the Horton experiment in order to demonstrate its effect on the separation bubble and pressure distribution.

Natural Transition Model Computations

\section{Gaster Experiment}

The experiment performed by Gaster (ref. 3) consisted of a separation bubble on a flat plate induced by the pressure field generated by the placement of an inverted airfoil near the plate. Vatsa and Carter (ref. 10) originally calculated the flow field corresponding to this experiment using the ALESEP analysis with a prescribed transition model. They found that the best match between the numerical results and the experimental data was obtained when instantaneous transition was prescribed at $\mathrm{s} / \mathrm{L}=1.0125$. The ALESEP analysis has now been used to predict the flow field for this experiment using the same computational grid and reference conditions used by Vatsa and Carter but with instantaneous transition predicted using the Roberts model. The free stream turbulence level for this experiment as used in equation (18) for the Roberts correlation is 0.0025 . Figure 5 shows a comparison of the predicted numerical results and the experimental data for this calculation. Excellent agreement is obtained between the present prediction and the data for this case as should be expected since the Gaster experimental data was part of the data base used by Roberts to formulate his model. With the use of the Roberts transition model, transition was predicted to occur at $s / L=1.025$. This location is quite close to the assumed position of transition and therefore explains the good agreement obtained between the two theoretical results in figure 5 .

\section{Gault NACA-0010 Airfoil}

The NACA-0010 modified airfoil tested experimentally by Gault (ref. 2) at an 8 degree angle of attack and a chord Reynolds number of $2.0 \times 10^{6}$ was calculated originally by Vatsa and Carter (ref. 10) and later in reference 16. In both instances, transition was initiated at $s / c=0.0283$ with a transition 
length of 0.0161 . The Dhawan and Narasimha (ref. 29) intermittency distribution was used to smoothly transist the flow from laminar to turbulent motion over the transition length. The intermittency factor reached a value of 0.5 at a location of $\mathrm{s} / \mathrm{c}=0.0350$. The predicted separation and reartachment locations for these calculations was located at $\mathrm{s} / \mathrm{c}=0.0156$ and $\mathrm{s} / \mathrm{c}=0.0439$, respectively. This case has been repeated using the Roberts instantaneous natural transition model with the same computational grid and reference conditions. The free stream turbulence level in this experiment was 0.002 .

Figure 6 shows the comparison between the present and previous interaction results and the experimental data. Transition was predicted to occur at $s / c=0.0375$ with the Roberts model which is somewhat downstream of that used earlier in the forced transition model. Although this difference corresponds to only about a 0.25 percent change in transition location in terms of the airfoil chord, it has a rather pronounced effect on the local pressure distribution in comparison with the experimental data. This result is not surprising as it was demonstrated in references 30 and 31 that the detailed flow properties near the transitional separation bubble are extremely sensitive to the transition location. In this case, a slight delay in transition has resulted in a larger separation bubble than that found previously and hence, a reduction in the peak suction pressure level. Nonetheless, it is encouraging that this natural transition model $c$ an be used in conjunction with the present interacting boundary layer theory to provide an approximate prediction of the complex flow field near a transitional separation bubble.

Gault NACA $66_{3}-018$ Airfoil

A final two-dimensional case which has been analyzed is the NACA $66_{3}-018$ mid-chord separation bubble tested experimentally by Gault (ref. 2) at a chord Reynolds number of $2.0 \times 10^{6}$. The free stream turbulence was 0.002 for this experiment. This case was originally calculated in reference 16 using the ALESEP analysis with the McDonald-Fish-Kreskovsky (refs. 32 and 33) turbulence model. This case has been recalculated in the present study using the CebeciSmith turbulence model (ref. 18) using the same computational grid and reference conditions as reported in reference 16. In this case, the best match between the numerical results and the experimental data was obtained when transition was specified to occur instantaneously at $x / c=0.725$. Figure 7 shows the predicted pressure distributions obtained with the Roberts model and the forced transition model in comparison with the experimental data of Gault. In contrast to the NACA-0010 case, Roberts' criterion predicts transition ahead of the "break" in the pressure distribution and hence a smaller separation bubble is deduced than that with the forced model. Specifically, transi$t$ ion was predicted at $x / c=0.690$ which corresponds to a change in the transition location from the prescribed location of 4 percent in terms of the airfoil chord. However, in terms of the predicted separation bubble length of 
the prescribed transition calculation in which separation is at $x / c=0.647$ and reattachment at $x / c=0.734$, this difference corresponds to about a $40 \%$ change. Roberts (ref. 11) found similar results for this case using his global interaction model.

The results of these two-dimensional separation bubble calculations have shown that in terms of a global airfoil prediction scheme, the Roberts correlation may be a good method to predict the approximate location of transition when a closed separation bubble is formed. However, if details of the flow field in the immediate vicinity of the separation bubble are required, modifications to this correlation are needed to improve the accuracy and generality.

Infinite Swept Wing

\section{Horton Experiment}

The extended ALESEP inviscid-viscous interaction procedure for infinite $s$ wept wings has been assessed with the experimental data of Horton (ref. 4). In Horton's experiment, a swept circular cylinder was placed above a 26.5 degree swept flat plate to induce a favorable followed by an adverse pressure gradient similar to that at the leading edge of a wing. Horton carefully controlled the experimental parameters to establish a closed transitional separation bubble on the flat plate in the adverse pressure gradient region of the flow. The spanwise repeatibility of measured pressure distributions showed that despite the presence of separation, the experiment satisfied the infinite swept wing conditions. The particular case chosen from this experiment for the present comparison was that for a free stream velocity of $51.9 \mathrm{ft.} / \mathrm{sec}$. The unit Reynolds number of the flow was $2.77 \times 10^{4}$ per inch and the free stream turbulence level was 0.0025 . The inviscid solution calculated by Woodward (ref. 34) for Horton's configuration was used as the inviscid reference solution. The corresponding reference displacement thickness distribution which al so appears explicitly in the Cauchy integral analysis (see ref. 10) was obtained from a direct (attached flow) fully turbulent boundary layer calculation in which the inviscid reference solution was used for the prescribed boundary layer edge velocity component. The upstream velocity profile for the interaction calculation was obtained from a direct laminar boundary layer calculation from the leading edge of the swept plate to a downstream position, $x=7.0$ inches, which is upstream of the strong interaction region. The interaction calculation was computed with 91 computational points spaced uniformly in the $x$-direction, normal to the leading edge, between $x=7.0$ and $x=16.0$ inches, and 100 points in the vertical direction with the minimum spacing placed at the wall. An underrelaxation parameter of 
0.5 associated with the update formula of the interaction scheme was used in both the windward and FLARE calculations which were performed for this case.

Figures 8 and 9 show good agreement between the predicted results and the experimental data for the pressure coefficient and displacement thickness distributions, respectively. These results are in part due to the excellent agreement between the transition location predicted by the Roberts correlation and the observed experimental transition location. The predicted separation, transition, and reattachment locations are indicated with arrows in figures 8 and 9. Separation was predicted to occur at $x=9.55$ inches. Transition from 1 aminar to turbulent flow was predicted by the Roberts correlation to occur at $x=11.1$ inches. The onset of transition causes a sudden increase in the pressure coefficient and a corresponding decrease in the displacement thickness with subsequent reattachment occuring a short distance downstream at $x=11.43$ inches. The onset of transition also corresponds to the sharp $r$ ise in the $x$-component of skin friction shown in figure 10. Excellent agreement is observed in figure 10 between the predicted and experimental separation and reattachment locations. For infinite swept wings, separation and reattachment correspond to lines parallel to the leading edge where $\mathrm{C}_{\mathrm{f}_{\mathrm{x}}}=0$. The $\mathrm{z}$-component of skin friction, also shown in figure 10, remains positive through the separated flow region. This outward spanwise migration of flow in the separation bubble is graphically shown in the predicted limiting streamline pattern of figure 11. In this figure, the 1 imiting streamlines are plotted in the absolute $X, Z$ coordinate system shown in figure 1 . The $X-d$ irection in this figure has been translated such that the start of the interaction calculation, which is located at $x=7.0$ inches ( $X=7.82$ inches), was at 0.0 . The stream1 ine pattern shown in figure 11 supports the trapped vortex pattern which Horton deduced from his experimental data. In this trapped vortex, the flow inside of the separation bubble consist of a swirling helical motion in the positive spanwise direction brought about by the superposition of the closed chordwise separation bubble with the outward flow in the spanwise direction.

Figure 12 shows a comparison of the predicted $u / u_{e}$ and $w / w_{e}$ velocity profiles corresponding to the $x$ - and $z$-directions, respectively, with the experimental data at eight different locations normal to the leading edge. The predicted velocity profiles for the calculation in which the FLARE approximation was used are also shown in this figure for comparison. The $\mathrm{u} / \mathrm{u}_{e}$ velocity profiles obtained with the windward and FLARE schemes, as shown in figure $12(\mathrm{a})$, are in close agreement with each other as well as with the experimental data. The largest differences between the predictions and the experimental data is in the region just downstream of where transition occurs $\left(x=11.1\right.$ inches). The predicted $w / w_{e}$ velocity profiles shown in figure $12(b)$ also show reasonably good agreement with the experimental data 
except in the region near transition. However, in contrast with the $u / u_{e}$ profiles the windward and FLARE results differ substantially in the separation bubble region. These differences indicate that windward differencing is important in quasi-three-dimensional and hence, should be important in threedimensional calculations.

\section{Influence of Wall Suction}

The accuracy of the wall suction boundary condition was tested by performing a direct, two-dimensional, laminar flat plate boundary layer calculation subject to a uniform wall suction distribution. Comparison of the computed results were made with the exact analytical solution given by Schlichting (ref. 35). The predicted boundary layer solution asymptotically approached the exact solution with streamwise distance from the leading edge of the flat plate. Negligible differences between the numerically predicted velocity profile displacement thickness, and skin friction and those of the exact solution were found for several levels of the prescribed wall suction.

An inviscid-viscous interaction analysis including wall suction was performed for the swept flat plate experiment of Horton to determine the influence of wall suction on the separation bubble and predicted pressure distribution. A uniform wall suction distribution at a level of $\left(\rho^{*} v^{*}\right)_{w}=-.01 \rho_{\infty}^{*} V_{\infty}^{*}$ where the asterisks denote dimensional quantities, imposed between the minimum pressure point at $x=8.9$ inches and the downstream location at $x=16.0$. The reference displacement thickness for this calculation was obtained from a direct laminar boundary layer calculation using the same wall suction distribution with the inviscid reference solution used as the prescribed boundary layer edge velocity. The same computational grid as that used in the previous interaction calculations for the Horton experiment was used for this case with wall suction.

Figure 13 shows the predicted results for the skin friction, displacement thickness, and wall pressure from the interaction calculations for the Horton swept plate subject to a uniform wall suction distribution. For this suction level the laminar flow remained attached as shown in figure 13(a) by the streamwise distributions of the $x$-component of the skin-friction. In this case the suction level was of a sufficient magnitude to result in an increase in skin friction and a corresponding decrease in the displacement thickness as shown in figure 13(b). Comparison of the results with those discussed previously for no suction demonstrate the strong influence that wall suction has on the overall flow. The pressure distribution shown in figure 13(c) is quite close to the inviscid reference pressure distribution which is expected since the flow remains attached in this case and only a weak interaction occurs between the viscous and inviscid flows. As expected the pressure 
plateau, characteristic of separated flows, is not obvious in this case since the flow remained attached.

Additional cases were attempted at reduced wall suction levels which resulted in flow separation for the Horton swept plate configuration. Difficulty was encountered in obtaining converged results for these cases which seemed to be due to the sensitivity of the results to the initial guess for the displacement thickness and due to the sensitivity of the calculation to the transition site location determined from the Roberts' criterion. Further work is needed to determine the precise cause of this iteration sensitivity.

\section{CONCLUDING REMARKS}

In this paper, the development of an inviscid-viscous interaction analysis for the prediction of airfoil transitional separation bubbles has been continued with the incorporation of the Roberts correlation for the prediction of the transition location within the bubble and the extension of the analysis to flows over infinite swept wings. Results from several two-dimensional cases indicate that the Roberts transition calculation is an accurate method for the prediction of the transition location within the separation bubble if detailed results in the vicinity of the separation bubble are not required. Modifications to this correlation should be made from carefully conducted experiments, however, to make it more accurate and general. Results have been shown which demonstrate that interacting boundary layer theory is capable of predicting transitional separation bubbles over infinite swept wings. These results provide valuable insight which will guide the future development of procedures for the fully three-dimensional flow field which exists in swept separation bubbles.

\section{ACKNOWLEDGEMENTS}

The work reported herein on the interpretation of the Roberts natural transition correlation as an empirical extension of linear stability theory for separated flows was performed in an independent research activity at UTRC. The authors wish to thank Dr. Harry $P$. Horton for providing additional information and technical discussions concerning his infinite swept plate experiment. Also, the authors express their gratitude to Mr. David Edwards for his help in implementing the Roberts transition correlation into the interaction procedure. 
1. Obara, C. J. and Holmes, B. J.: Flight-Measured Laminar Boundary-Layer Transition Phenomena Including Stability Theory Analysis, NASA TP 2417 , Apri1, 1985.

2. Gault, D. E.: An Experimental Investigation of Separated Laminar Flow, NASA TN 3503, September 1955.

3. Gaster, M.: The Structure and Behavior of Laminar Separation Bubbles, AGARD Conference Proceedings 4, pp. 819-854, 1966.

4. Horton, H. P.: Laminar Separation Bubbles in Two and Three Dimensional Incompressible Flow, Ph.D. Thesis, University of London, (Queen Mary College), 1968 .

5. Ntim, B. A.: A Theoretical and Experimental Investigation of Separation Bubbles, Ph.D. Thesis, University of London (Queen Mary College), 1969.

6. Mueller, T. J. and Batill, S. M.: Experimental Studies of the Laminar Separation Bubbles on a Two-Dimensional Airfoil at Low Reynolds Numbers, AIAA Paper $80-1440,1980$.

7. Bursnal1, W. J. and Loftin, L. K., Jr.: Experimental Investigation of Localized Regions of Laminar-Boundary-Layer Separation, NACA TN 233, April, 1951 .

8. Gleyzes, C., Cousteix, J. and Bonnet, J. L.: A Calculation Method of Leading Edge Separation Bubbles, Second Symposium on Numerical and Physical Aspects of Aerodynamic Flows, California State University, January 1983.

9. Kwon, O. K., and Pletcher, R. H.: Prediction of Incompressible Separated Boundary Layer Including Viscous-Inviscid Interaction, Journal Fluid Engineering, Vol. 3, 1958.

10. Vatsa, V. N. and Carter, J. E.: Analysis of Airfoil Leading-Edge Separation Bubbles, AIAA Journal, December 1984, pp. 1697-1704.

11. Roberts, W. B.,: Calculation of Laminar Separation Bubbles and Their Effect on Airfoil Performance, AIAA Journal, Vo1. 18, No. 1, pp. 25-30, January 1980 .

12. Mack, L. M.: Transition Prediction and Linear Stability Theory. AGARD CP-224, Pp.1-1 to 1-22, 1977 . 
13. Carter, J. E.: A New Boundary Layer Inviscid Iteration Technique for Separated Flow, AIAA Paper 79-1450, July 1979.

14. Moore, F. K.: Displacement Effect of a Three-Dimensional Boundary Layer, NACA Report 1124, 1953.

15. Carter, J. E.: Inverse Boundary-Layer Theory and Comparison With Experiment, NASA TP-1208, September 1978.

16. Davis, R. L. and Carter, J. E.: Analysis of Airfoil Transitional Separation Bubbles, AIAA Paper 84-1613, 1984.

17. Reyhner, T. A. and Flugge-Lotz, I.: The Interaction of a Shock Wave with a Laminar Boundary Layer, Int. Journal of Non-Linear Mech., Vol.3, No. 2, June 1968, pp. 173-179.

18. Cebeci, T. and Smith, A. M. O.: Analysis of Turbulent Boundary Layers, Academic Press, 1974.

19. Cebeci, T., Kaups, K., Mosinskis, G. J., and Rehn, J. A.: Some Problems of the Calculation of Three-Dimensional Boundary Layer Flows on General Configurations, NASA CR-2285, July 1973.

20. Kim, J., Kline, S. J., and Johnston, J. P.,: Investigation of a Reattaching Turbulent Shear Layer: Flow Over a Backward-Facing Step, Trans. of the ASME, Vo1. 102, Sept. 1980, pp. $302-308$.

21. Cebeci, T., Clark, R. W., Chang, K. C., Halsey, N. D. and Lee, K.: Airfoils with Separation and the Resulting Wakes, Third Symposium on Numerical and Physical Aspects of Aerodynamic Flows, California St. University, January 1985.

22. Dryden, H. L.: Transition from Laminar to Turbulent FLow in "Turbulent Flows and Heat Transfer". (C.C. Lin, ed.), 1959, Princeton Univ., Press, N. J., pp. 1-74.

23. Stewartson, K.: Further Solutions of the Falkner-Skan Equation, Proc. Camb. Phil. Soc., Vol. 50, pp.454-465, 1954.

24. Christian, J. W. and Hankey, W. L.: Similar Solutions of the Attached and Separated Compressible Boundary Layer with Heat Transfer and Pressure Gradient, ARL 70-0023, 1970.

25. Roberts, W. B.: A Study of the Effect of Reynolds Number and Laminar Separation Bubbles on the Flow Through Axial Compressor Cascades, D.SC. Thesis, U. Libre de Bruxelles and VKI, May 1973. 
26. Horton, H. P.: A Semi-Empirical Theory for the Growth and Bursting of Laminar Separation Bubbles, ARC CP-1073, 1969.

27. Evans, B. J.: Effects of the Free Stream Turbulence on Blade Performance in a Compressor Cascade, Cambridge Univ. Engineering Dept. Turbo/TR25, 1971 .

28. Gaster, M.: The Structure and Behavior of Laminar Separation Bubbles, NPL Aero. Report 1181, ARC 28.226, 1966.

29. Dhawan, S. and Narasimha, R.: Some Properties of Boundary Layer Flow During Transition from Laminar to Turbulent Motion, Journal Fluid Mechanics, Vol. 3, 1958.

30. Carter, J. E. and Vatsa, V. N.: Analysis of Airfoil Leading Edge Separation Bubbles, NASA CR-165935, May 1982.

31. Davis, R. L. and Carter, J. E.: Analysis of Airfoil Transitional Separa$t$ ion Bubbles, NASA CR-3791, 1984.

32. McDonald, H. and Fish, R. W.: Practical Calculation of Transitional Boundary Layers, Int. Journal Heat Mass Transfer, Vol. 16, pp. 1729 $1944,1973$.

33. McDonald, H. and Kreskovsky, J. P.: Effect of Free Stream Turbulence on the Turbulent Boundary Layer, Int. Journal Heat Mass Transfer, Vol. 17, pp. $705-716,1974$.

34. Woodward, D. S.: An Investigation of the Parameters Controlling the Behaviour of Laminar Separation Bubbles, Royal Aircraft-Establishment Tech. Memo Aero 1003, August 1967.

35. Schlichting, H.: Boundary-Layer Theory, McGraw-Hill Publishers, 1968. 


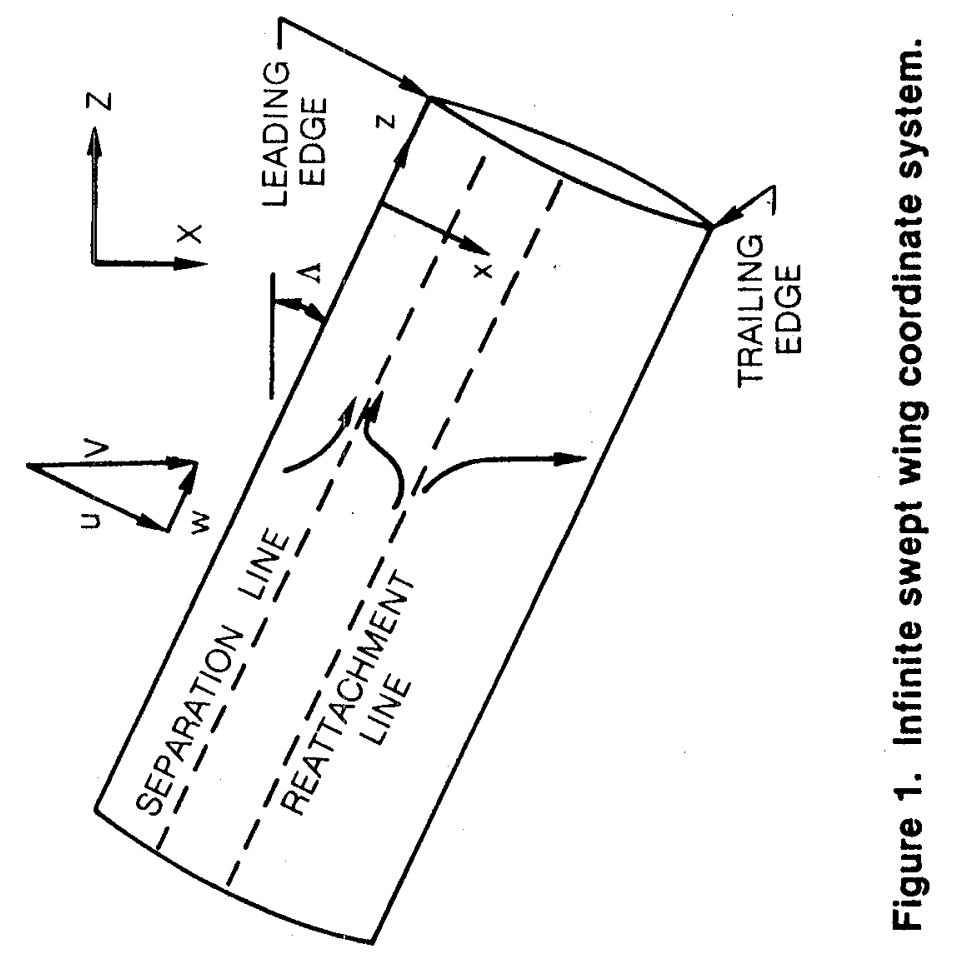




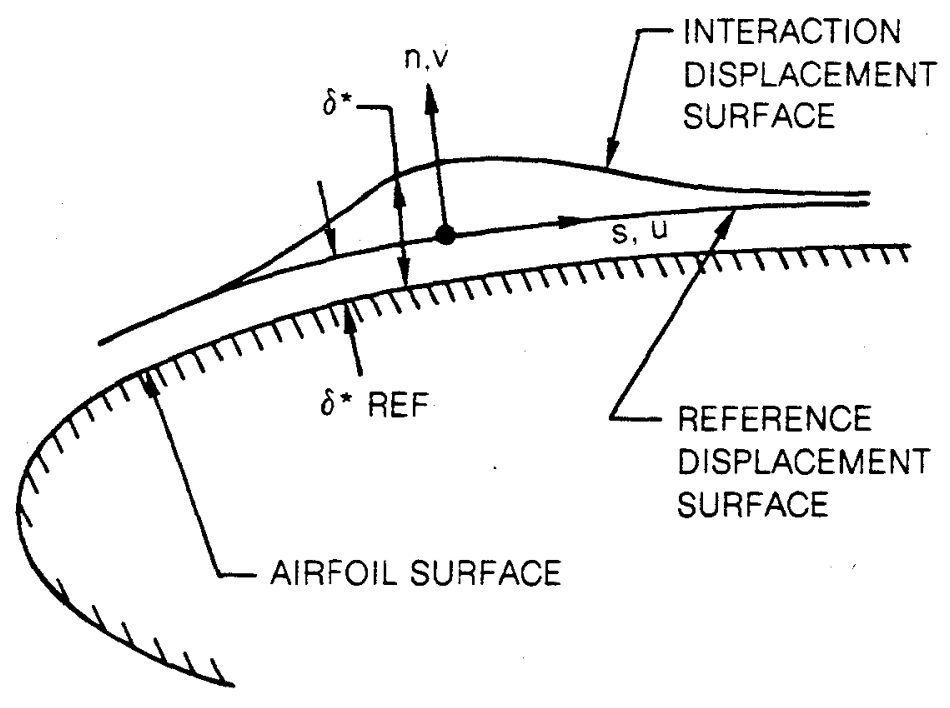

Figure 2. Local interaction region coordinate system. 


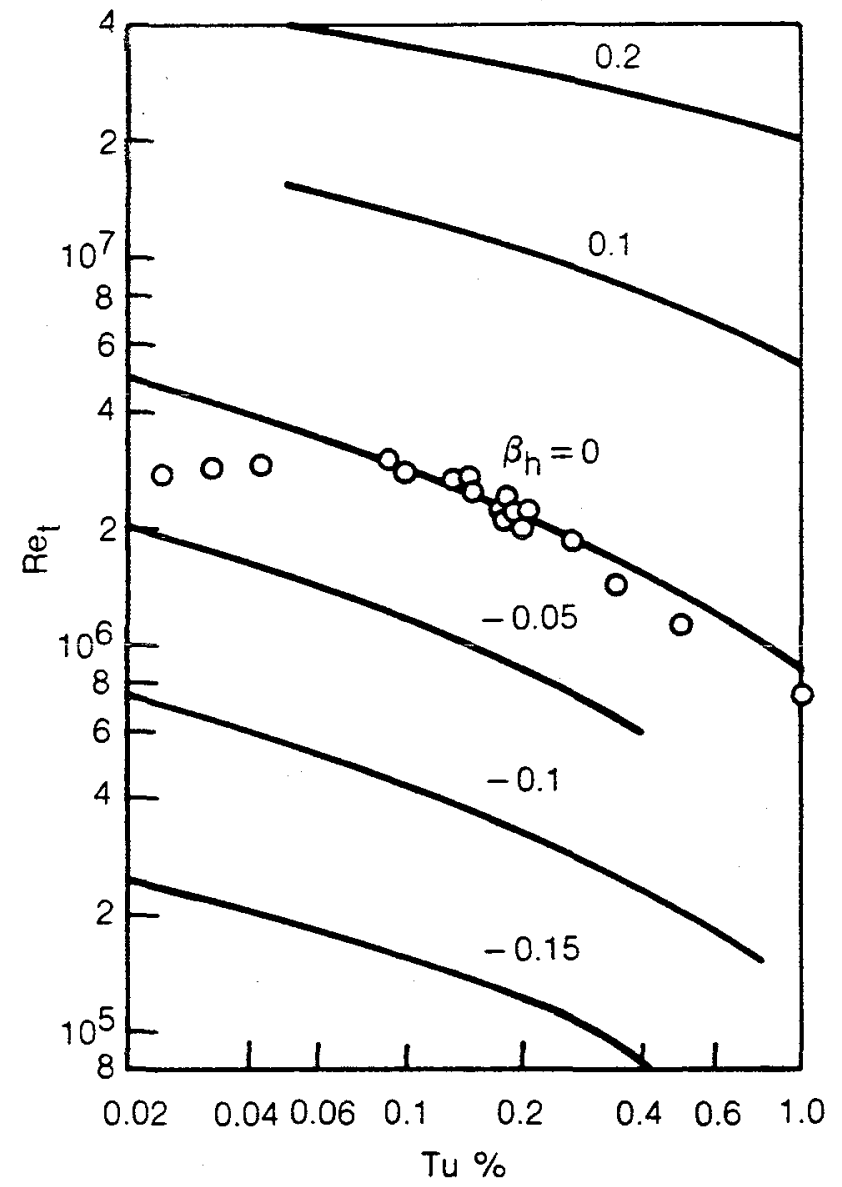

Figure 3. Effect of free stream turbulence on the transition Reynolds number of Falkner-Skan boundary layers, Mack (Ref. 12). 


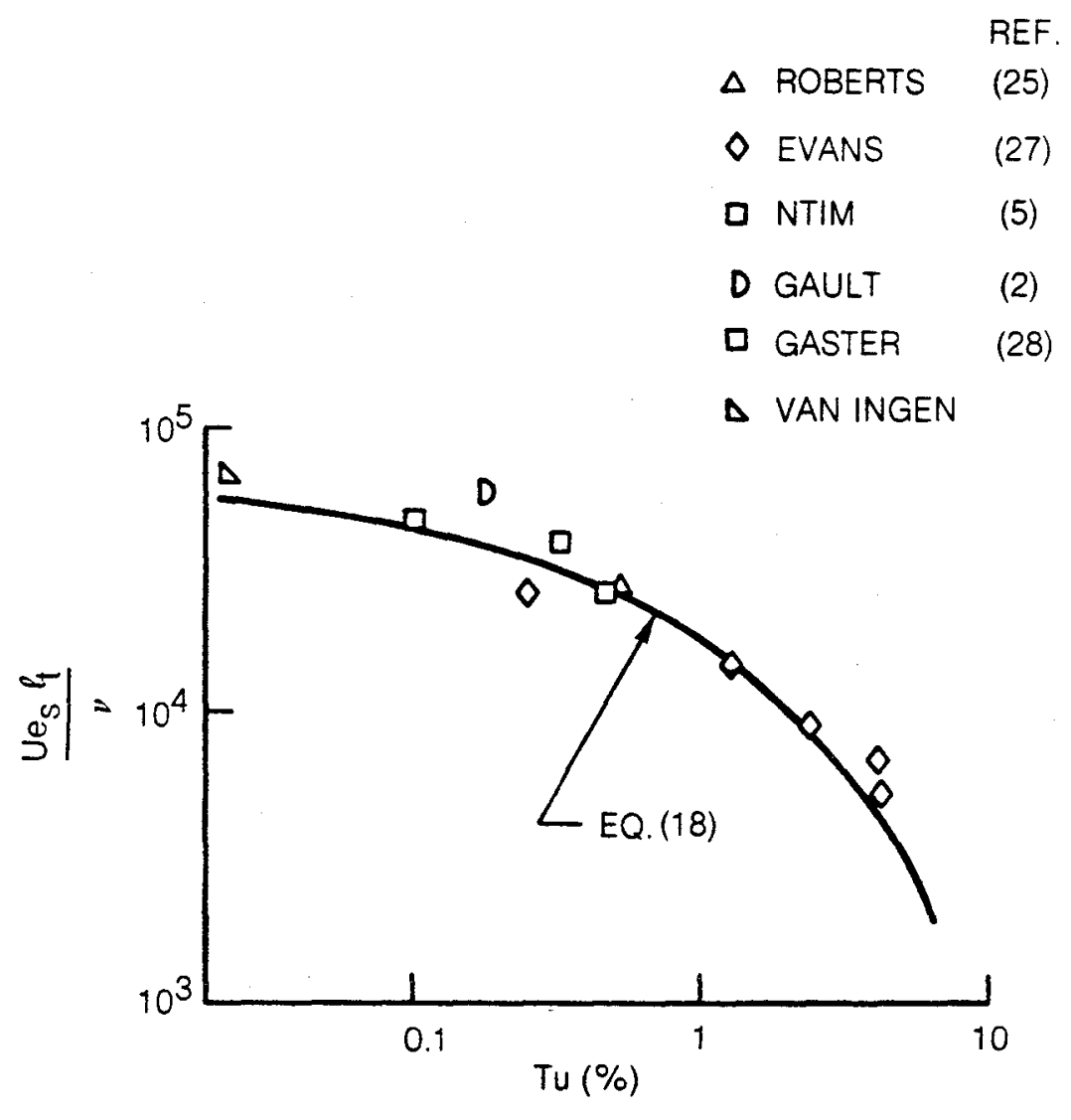

Figure 4. Roberts type correlation of experimental data. 


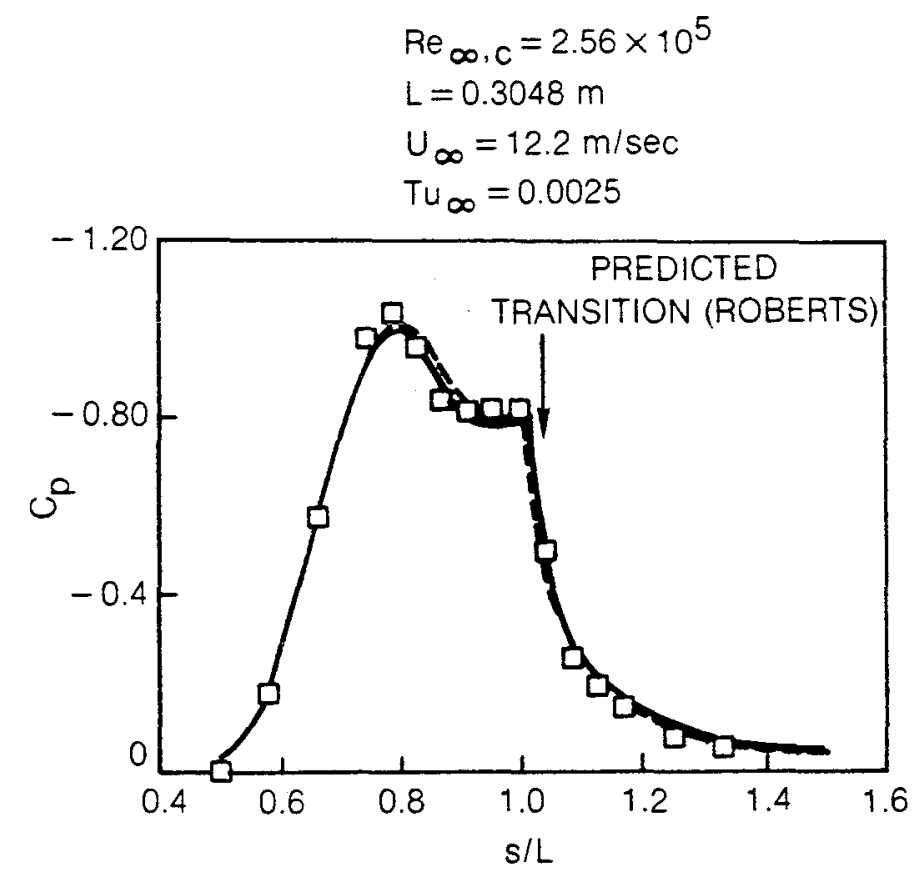

Figure 5. Comparison of predicted pressure distribution with Gaster experimental data. 


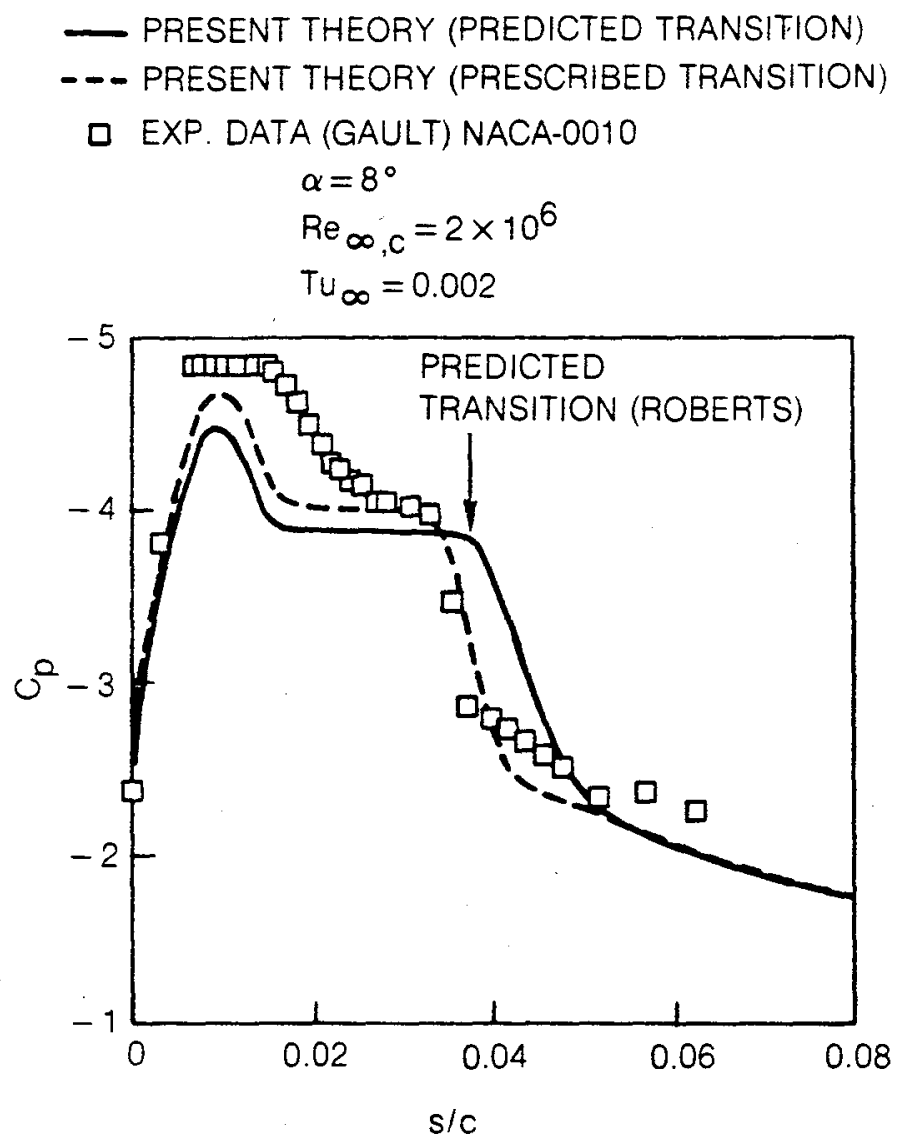

Figure 6. Comparison of predicted pressure distribution with Gault experimental data for NACA-0010 (modified) airfoil. 
- PRESENT THEORY (PREDICTED TRANSITION)

$\cdots$ PRESENT THEORY (PRESCRIBED TRANSITION)

口 EXP. DATA (GAULT) NACA $66_{3}-018$

$$
\begin{aligned}
& \alpha=0^{\circ} \\
& R e_{C}=2 \times 10^{6} \\
& T u_{\infty}=0.002
\end{aligned}
$$

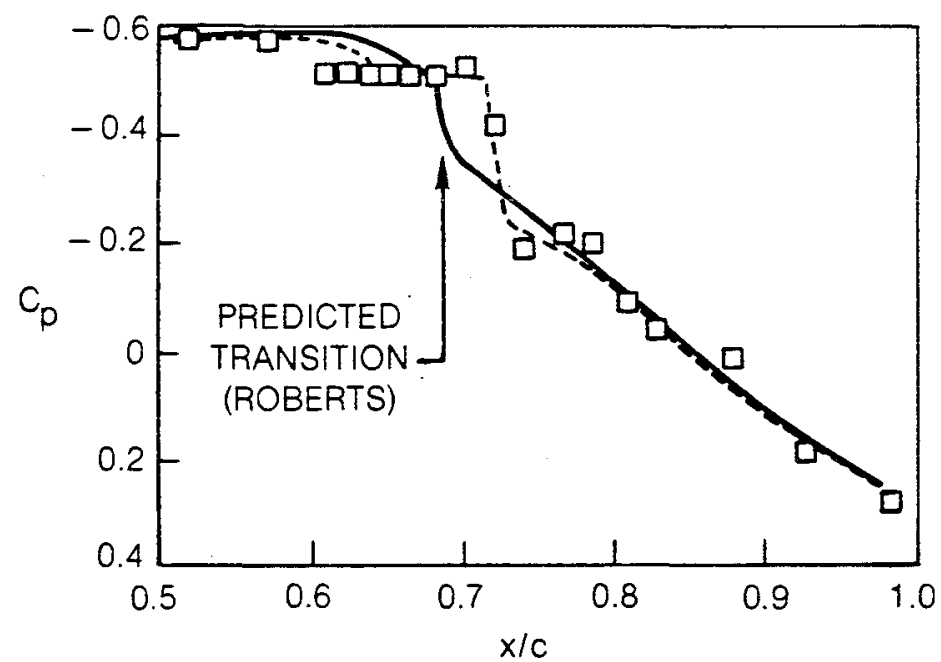

Figure 7. Comparison of predicted pressure distribution with Gault experimental data for NACA $66_{3}, 018$ airfoil. 


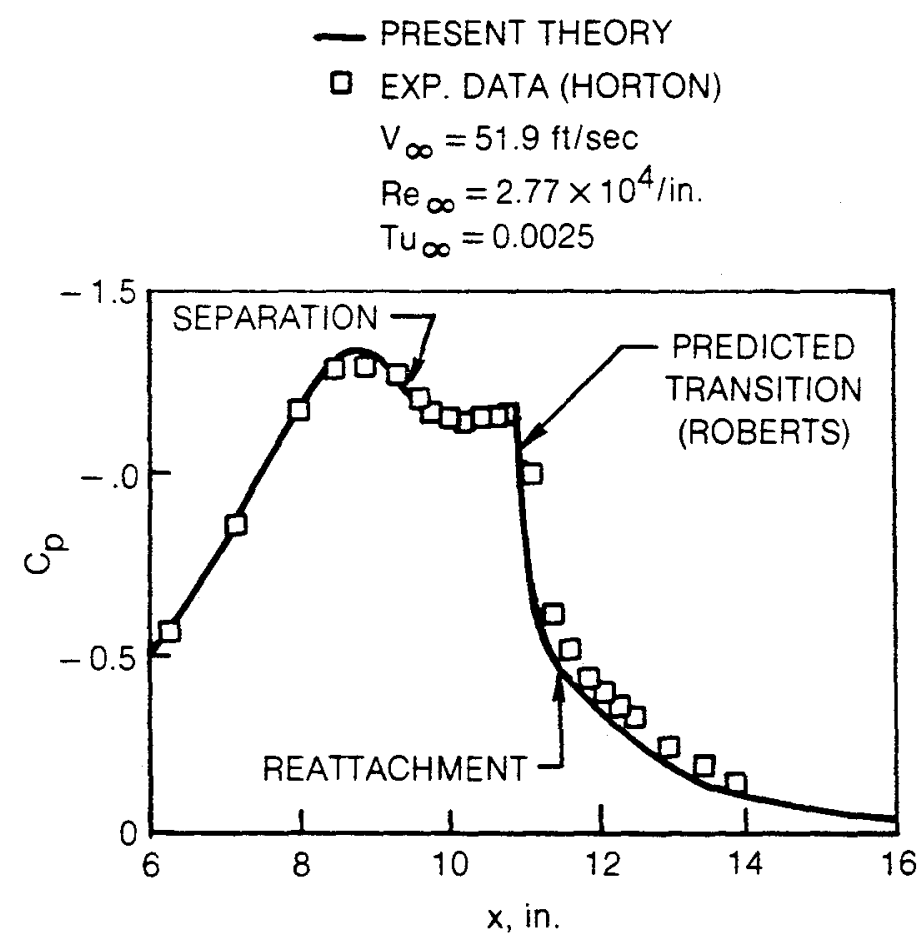

Figure 8. Comparison of predicted pressure distribution with Horton swept plate experimental

data. 


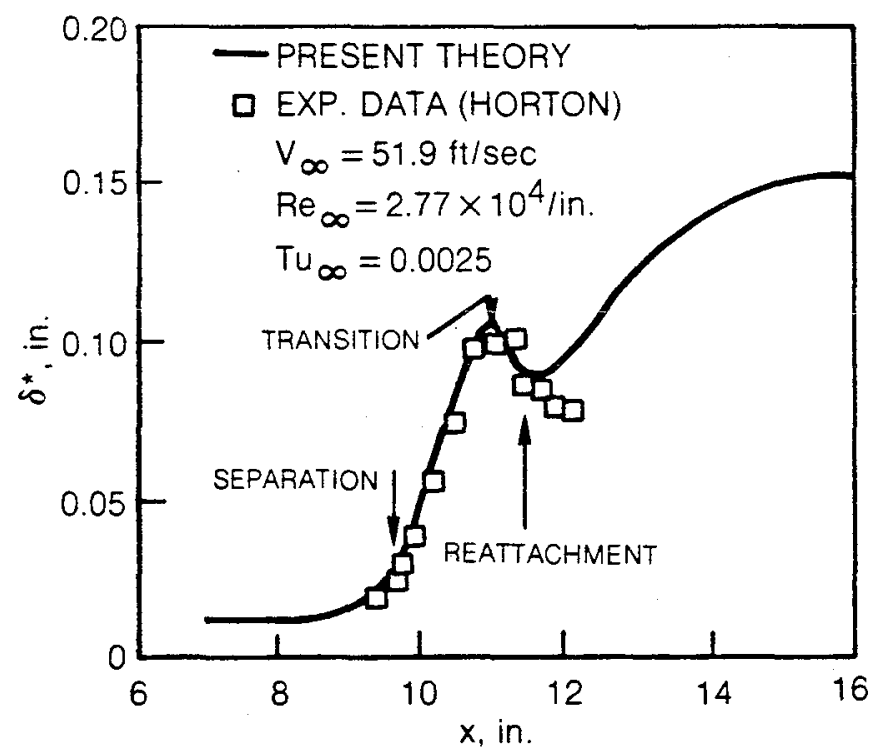

Figure 9. Comparison of predicted displacement thickness distribution with Horton swept plate experimental data. 


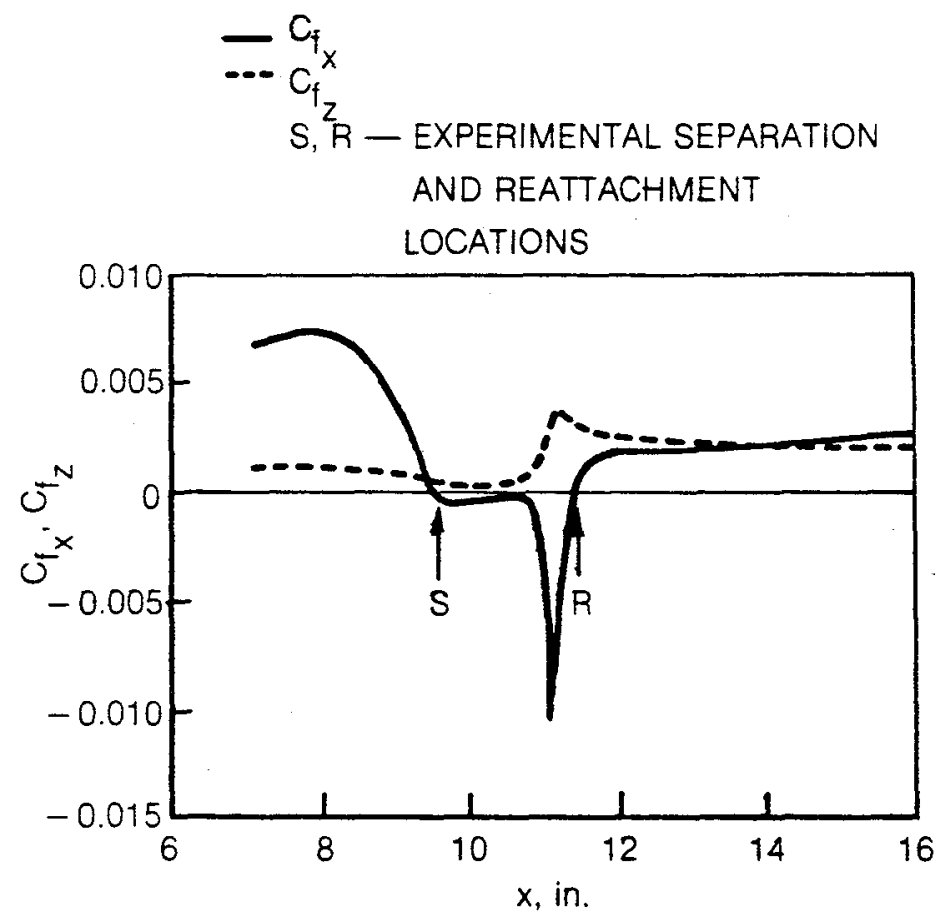

Figure 10. Predicted skin friction components for Horton swept plate experimental data. 


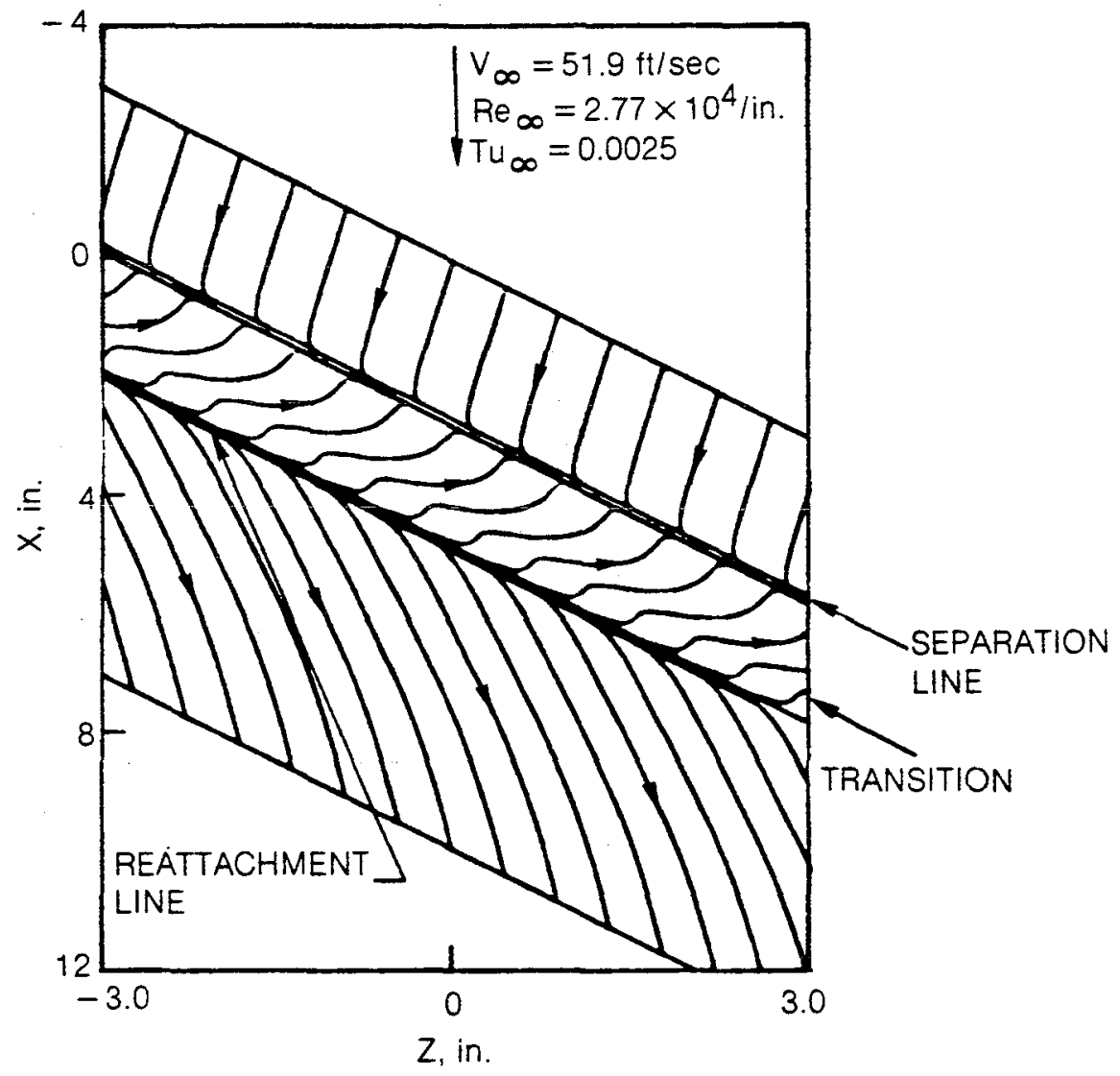

Figure 11. Predicted limiting streamlines corresponding to Horton swept plate experiment. 

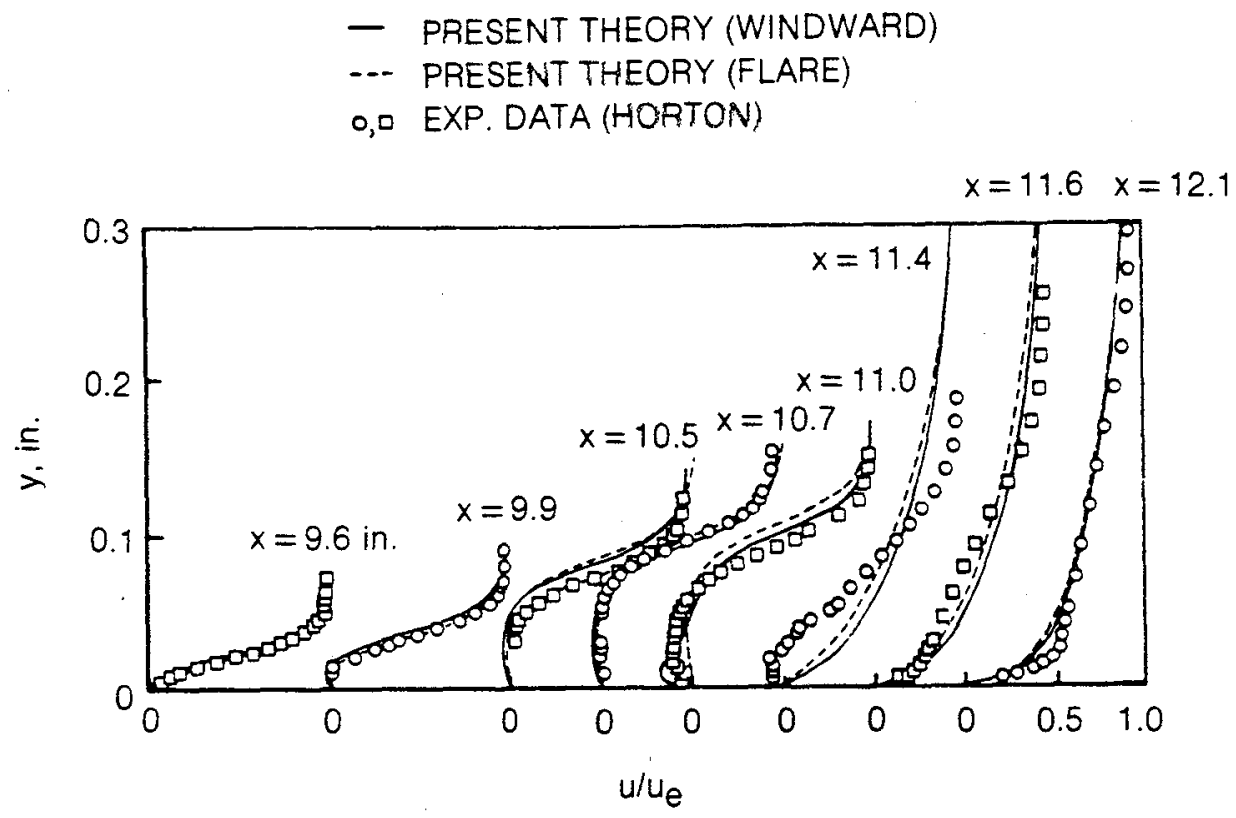

(a) VELOCITY PROFILES NORMAL TO LEADING EDGE

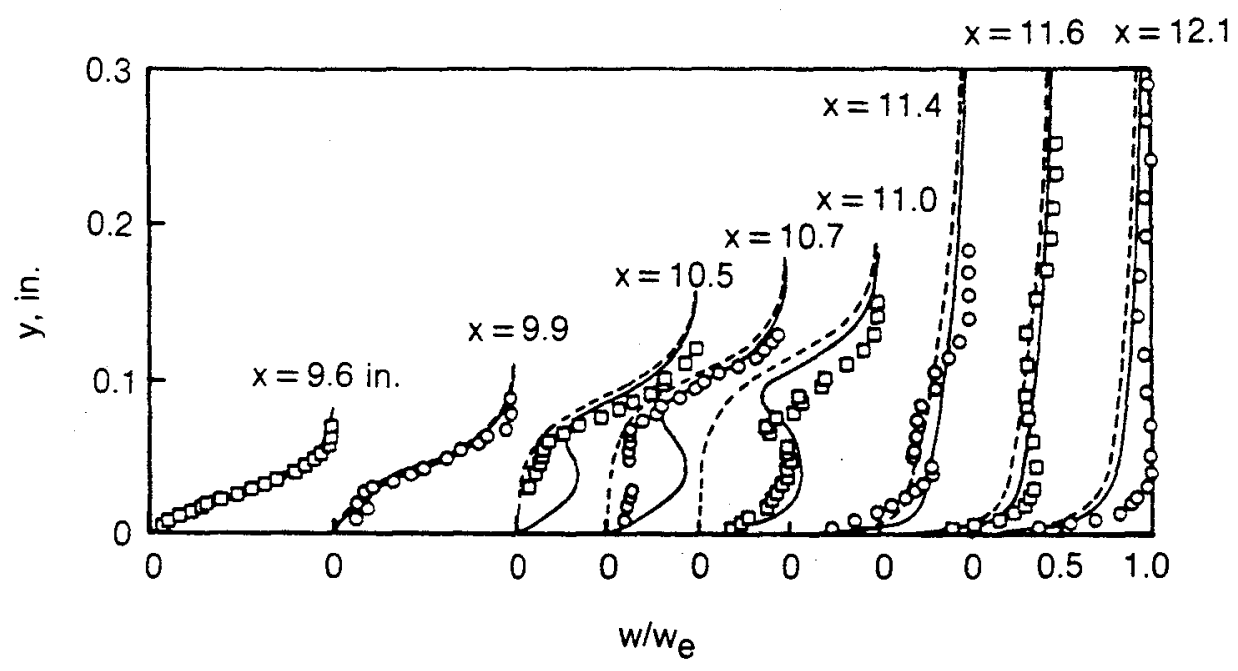

(b) VELOCITY PROFILES TANGENT TO LEADING EDGE

Figure 12. Comparison of predicted results with Horton swept plate experimental data. 


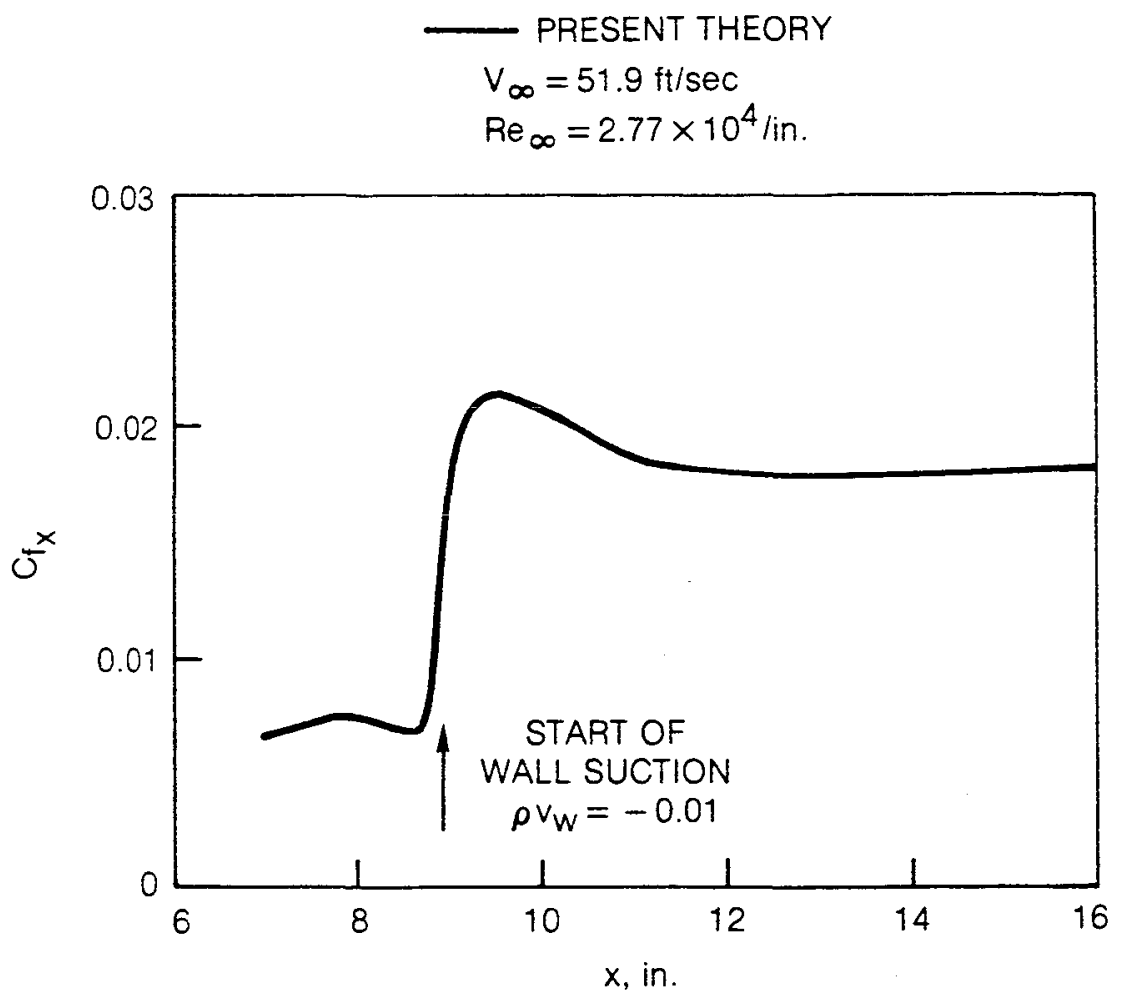

Figure 13 (a). Predicted axial component of skin friction for Horton swept plate experiment with wall suction. 

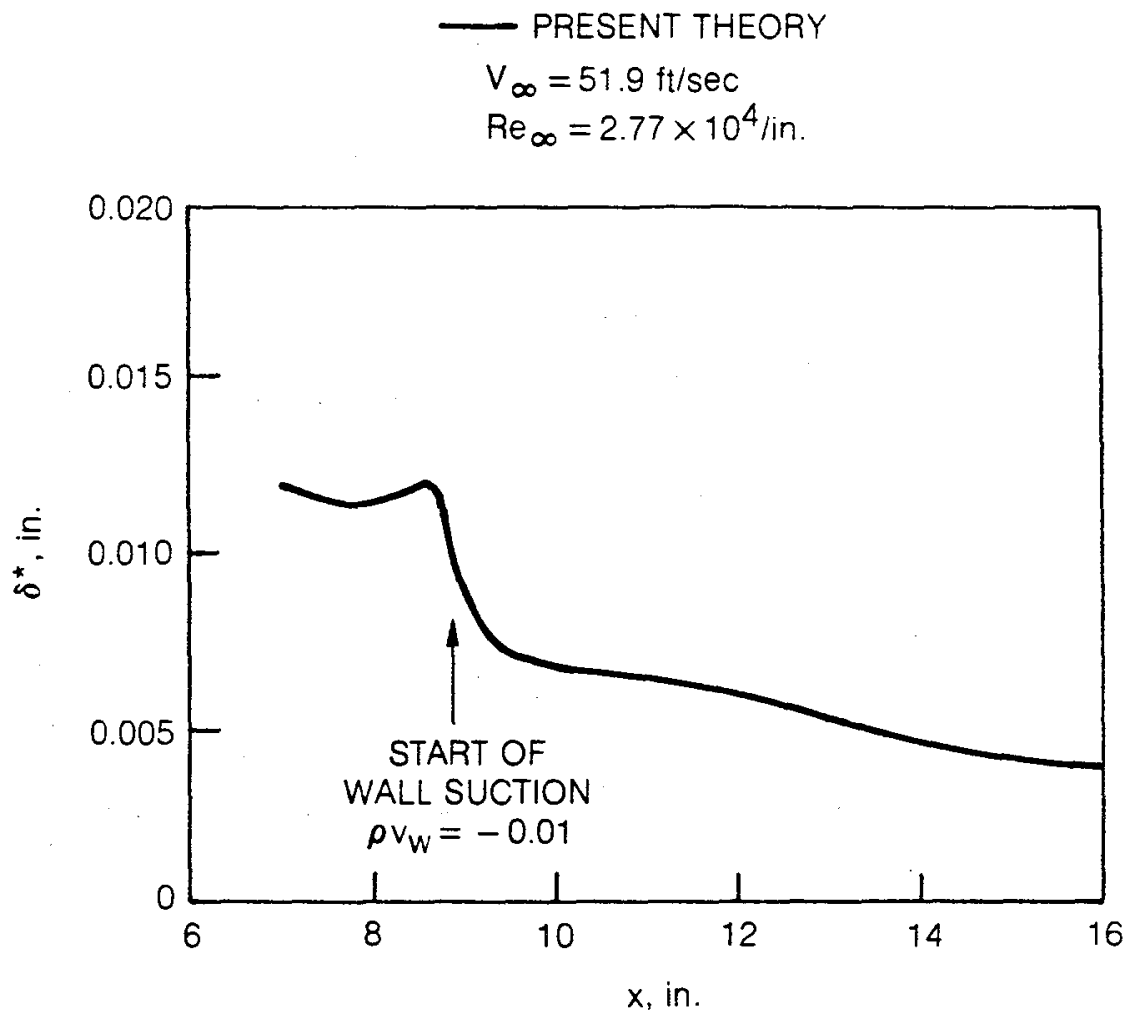

Figure 13 (b). Predicted displacement thickness for Horton swept plate experiment with wall suction. 


$$
\begin{aligned}
& \text { PRESENT THEORY } \\
& V_{\infty}=51.9 \mathrm{ft} / \mathrm{sec} \\
& \operatorname{Re}_{\infty}=2.77 \times 10^{4} / \mathrm{in} .
\end{aligned}
$$

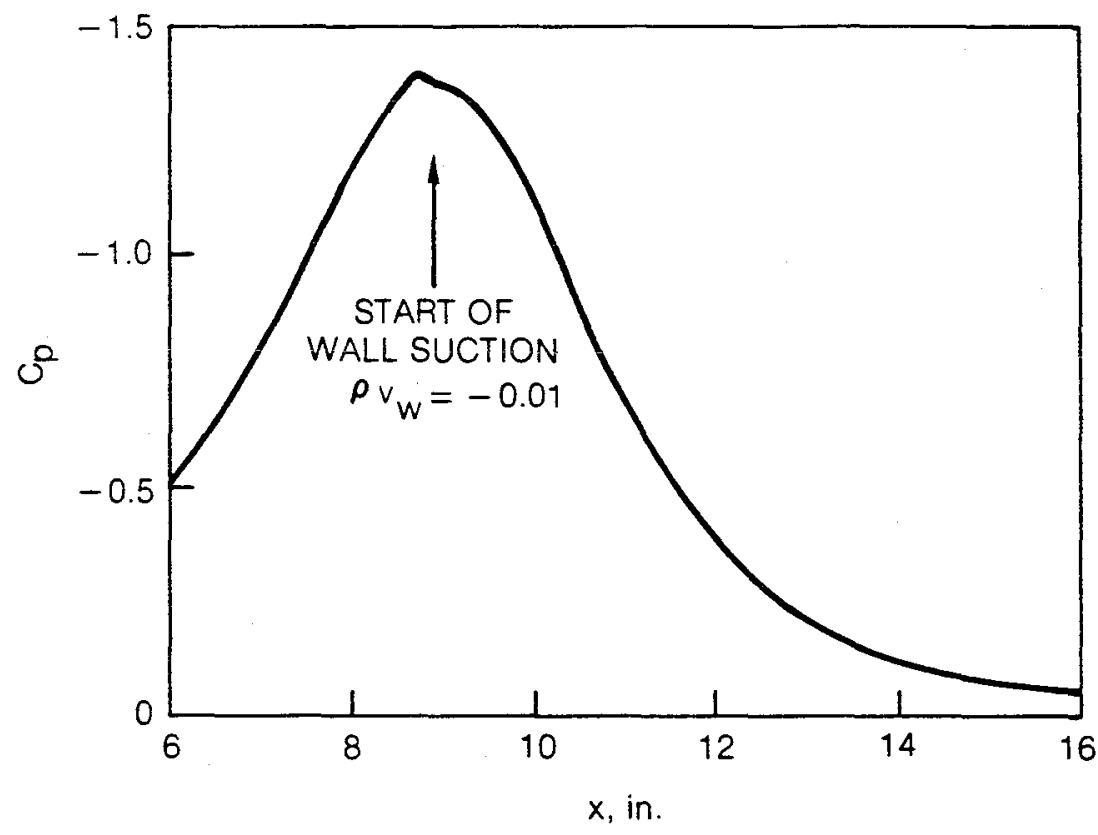

Figure 13 (c). Predicted pressure distribution for Horton swept plate experiment with wall suction. 


\begin{tabular}{|c|c|c|}
\hline $\begin{array}{l}\text { 1. Report No } \\
\text { NASA CR-3956 }\end{array}$ & 2. Government Accussion No. & 3. Rocipient's Coulos No. \\
\hline \multirow{2}{*}{\multicolumn{2}{|c|}{$\begin{array}{l}\text { 4. Tnle mo sumile } \\
\text { Analysis of Transitional Separation Bubbles } \\
\text { on Infinite Swept Wings }\end{array}$}} & $\begin{array}{l}\text { B. Aepon Dorte } \\
\text { June } 1986\end{array}$ \\
\hline & & 6. Performing Orgenization Code \\
\hline \multicolumn{2}{|c|}{$\begin{array}{l}\text { 7. Aurnor(s) } \\
\text { R. L. Davis and J. E. Carter }\end{array}$} & B. Pertorming Orgenization Report No \\
\hline & 10. Work \\
\hline \multicolumn{2}{|c|}{$\begin{array}{l}\text { 9. forming Organization Nome and Adoress } \\
\text { UNITED TECHNOLOGIES RESEARCH CENTER } \\
\text { S1lver Lane } \\
\text { East Hartford, CT } 06108\end{array}$} & $\begin{array}{l}\text { 11. Contrect or Grent No. } \\
\text { NAS1 }-16585\end{array}$ \\
\hline \multirow{2}{*}{\multicolumn{2}{|c|}{$\begin{array}{l}12 \text { Soonsoring Apency Name and Adders } \\
\text { National Aeronautics and Space Administration } \\
\text { Washington, D.C. } 20546\end{array}$}} & $\begin{array}{l}\text { 13. Troe of Aeport and Period Covered } \\
\text { Contractor Report }\end{array}$ \\
\hline & & 14. Sponsoring Agency Coose \\
\hline \multicolumn{3}{|c|}{$\begin{array}{l}15 \text { Supplementary Notes } \\
\text { Langley Technical Monitor: Joel L. Everhart }\end{array}$} \\
\hline \multicolumn{3}{|c|}{$\begin{array}{l}\text { 16. Abstract A previously developed two-dimensional local inviscid-viscous inter- } \\
\text { action technique for the analysis of airfoil transitional separation bubbles, } \\
\text { ALESEP (Airfoil Leading Edge Separation), has been extended for the calcula- } \\
\text { tion of transitional separation bubbles over infinite swept wings. As part of } \\
\text { this effort, Roberts empirical correlation, which is interpreted as a sepa- } \\
\text { rated flow empirical extension of Mack's stability theory for attached flows, } \\
\text { has been incorporated into the ALESEP procedure for the prediction of the } \\
\text { transition location within the separation bubble. In addition, the viscous } \\
\text { procedure used in the ALESEP technique has been modified to allow for wall } \\
\text { suction. A series of two-dimensional calculations are presented as a verifi- } \\
\text { cation of the prediction capability of the Interaction technique with the } \\
\text { Roberts' transition model. Numerical tests have shown that this two-dimen- } \\
\text { sional natural transition correlation may also be applied to transitional } \\
\text { separation bubbles over infinite swept wings. Results of the interaction pro- } \\
\text { cedure are compared with Horton's detailed experimental data for separated } \\
\text { flow over a swept plate which demonstrates the accuracy of the present tech- } \\
\text { nique. Wall suction has been applied to a similar interaction calculation to } \\
\text { demonstrate its effect on the separation bubble. The principal conclusion of } \\
\text { this paper is that the prediction of transitional separation bubbles over two- } \\
\text { dimensional or infinite swept geometries is now possible using the present } \\
\text { interacting boundary layer approach. }\end{array}$} \\
\hline \multicolumn{2}{|c|}{$\begin{array}{l}\text { 17. Key words (Suggested by Author(s)! } \\
\text { Interaction } \\
\text { Separation bubble } \\
\text { Viscous } \\
\text { Transitional } \\
\text { Airfoil and infinite swept wing } \\
\text { separation }\end{array}$} & d - Unlimited \\
\hline \multicolumn{2}{|l|}{$\begin{array}{l}\text { 19. Security Gossir. (of this report) } \\
\text { Unclassif ied }\end{array}$} & \begin{tabular}{|c|r|}
$\begin{array}{c}\text { 21. No. of Pages } \\
40\end{array}$ & $\begin{array}{r}\text { 22. Mice } \\
\mathrm{AO} 3\end{array}$ \\
\end{tabular} \\
\hline
\end{tabular}

For sale by the Nationa! Technical Iniormation Service, Springtield, Virginia 2215] 
<smiles>C1CC2CC12</smiles> 